\title{
Phase Structure and Biodegradation of the Bacterial Poly(3-hydroxybutyric acid)/Chemosynthetic Poly(3-hydroxypropionic acid) Blend
}

\author{
Amin CaO, Naoki Asakawa, Naoko Yoshie, and Yoshio InouE ${ }^{\dagger}$ \\ Department of Biomolecular Engineering, Tokyo Institute of Technology, \\ 4259 Nagatsuta, Midori-ku, Yokohama 226-8501, Japan
}

(Received April 24, 1998)

\begin{abstract}
Two different aliphatic polyesters, bacterially synthesized polyester poly(3-hydroxybutyric acid) [P(3HB)] and chemically synthesized poly(3-hydoxypropionc acid) $[\mathrm{P}(3 \mathrm{HP})]$, were blended via solvent casting. By differential scanning calorimetry, polarized optical microscopy, wide-angle X-ray diffractometer and dynamic mechanical thermal analytical instrument, thermal and crystallization behavior and dynamic mechanical relaxation of the as-prepared binary blends were systematically studied. Immiscible properties were ambiguously demonstrated for these blends over the whole range of constituent composition. Glass transition temperature and proton spin diffusion times $\left(T_{1}^{\mathrm{H}}\right.$ and $\left.T_{1 \rho}^{\mathrm{H}}\right)$ obtained by the high-resolution solid state ${ }^{13} \mathrm{C}$ NMR measurements indicated that the blend system was immiscible not only on an observation scale of DSC (about $10 \mathrm{~nm}$ ), but on a $T_{1}^{\mathrm{H}}$ scale (several tens of $\mathrm{nm}$ ). Enzymatic biodegradation of the blend samples by extracellular $\mathrm{P}(3 \mathrm{HB})$-depolymerase from the bacterium strain $A$. faecalis $T$ l showed an approximately linear relation between the degradation rate and the component composition. In addition, on the basis of biochemical oxygen demand (BOD), pure $\mathrm{P}(3 \mathrm{HP})$ could not be biodegraded in the river water, while environmental biodegradability was confirmed when it presents as one constitutive component of the binary $\mathrm{P}(3 \mathrm{HB}) / \mathrm{P}(3 \mathrm{HP})$ blend.

KEY WORDS P(3HB)/P(3HP) Blend / Thermal and Crystallization Behavior/Morphology of Spherulite/ Dynamic Mechanical Thermal Analysis/ Proton Spin Diffusion/ Miscible Property/ Enzymatical and Environmental Biodegradation Behavior /
\end{abstract}

Poly(hydroxyalkanoic acid)s (PHAs) which accumulate as the intracellular storage compounds by the widely distributed microorganisms in the environments, are now of increasing importance due to more serious problem in plastical waste disposal. ${ }^{1-4}$ Because of their bacterial origins, this class of aliphatic polyesters can be environmentally degraded into water and carbon dioxide, exhibiting unique features distinguishable from those of the conventional plastics. A wide range of bacterial biodegradable polyesters and copolyesters have been developed for various technical applications by constructing the desired repeating unit structures. ${ }^{5}$ Poly(3hydroxybutyric acid) $[\mathrm{P}(3 \mathrm{HB})]$, a representative of PHAs, is a thermoplastics known to be suffered from its high melting point, excessive brittleness and poor impact resistance in applications. ${ }^{2-4}$ Although efforts have been made to bacterially co-polymerize $3 \mathrm{HB}$ repeating units with other monomers such as 3-hydroxypropionic acid (3HP), ${ }^{6-8}$ 3-hydroxyvaleric acid (3HV), ${ }^{9}$ 4-hydroxybutyric acid (4HB),, $10-12$ and so forth, can improve its deficiencies. However, the considerably high cost of the cultivable substrates and/or precursor-substrates in fermentation impede broader applications of the bacterial polyesters. As an alternative route to provide materials with desirable properties, blending the natural $\mathrm{P}(3 \mathrm{HB})$ with a secondary constituent is effective without loss of favorable features of biodegradability and biocompatibility. ${ }^{13}$ Binary blends of bacterial $\mathrm{P}(3 \mathrm{HB}) /$ chemosynthetic $\mathrm{P}(3 \mathrm{HB})$ with various tacticities, ${ }^{14-16} \mathrm{P}(3 \mathrm{HB}) /$ poly(ethylene oxide) (PEO), ${ }^{17-19} \mathrm{P}(3 \mathrm{HB}) /$ poly(vinyl alcohol) $(\mathrm{PVA}),{ }^{20} \mathrm{P}(3 \mathrm{HB}) / \mathrm{P}(3 \mathrm{HB}-c o-3 \mathrm{HV}){ }^{13}$ have been extensively studied by many investigators.

Recently, Nishida et al. $^{21}$ have reported that the chemically synthesized poly(3-hydroxypropionic acid)

\footnotetext{
$\dagger$ To whom correspondence should be addressed.
}

$[\mathrm{P}(3 \mathrm{HP})]$ could be degraded by the widely distributed microorganisms in the environment, and is an analogue of substrate recognizable by $\mathrm{P}(3 \mathrm{HB})$ - or polycaprolatone (PCL)-degrader. Kasuya et ll $^{22}$ and Kumagai et al. ${ }^{23}$ found that $\mathrm{P}(3 \mathrm{HP})$ could also be enzymatically degraded by the extracellular $\mathrm{P}(3 \mathrm{HB})$-depolymerases from genera of environmental microorganisms. With regard to physicomechanical aspects of the $\mathrm{P}(3 \mathrm{HP})$, an ultimate elongation rate up to $540 \%$ higher than that of $\mathrm{P}(3 \mathrm{HB})$ (4\%) was reported by Yamashita et al., ${ }^{24}$ and particularly demonstrating much stronger modulus of either uniaxial- or diaxial-drawn P(3HP) films than those of polypropylene (PP) and high-density polyethylene (HDPE). Hence, the binary blend consisting of two biodegradable polyesters $\mathrm{P}(3 \mathrm{HB})$ and $\mathrm{P}(3 \mathrm{HP})$ is of great interest.

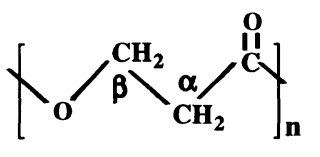

P(3HP)<smiles>CO[C@@H](C)C(C)=O</smiles>

P(3HB)
This paper reports the phase structure and biodegradation behavior of the binary $\mathrm{P}(3 \mathrm{HB}) / \mathrm{P}(3 \mathrm{HP})$ blend. Thermal and crystallization behavior were investigated by differential scanning calorimetry, polarized optical microscopy and X-ray diffractometer for the blend films prepared via solvent casting. Dynamic mechanical thermal analyses were made to investigate mechanical and miscible behavior. High-resolution solid state ${ }^{13} \mathrm{C}$ NMR measurements were performed to study two important parameters in terms of proton spin-lattice relaxation in laboratory and rotating frames $\left(T_{1}^{\mathrm{H}}, T_{1 \rho}^{\mathrm{H}}\right)$, and assessment of miscibility on an observation scale different from those by DSC and DMTA was studied. 
The enzymatic degradation behavior of the $\mathrm{P}(3 \mathrm{HB})$ / $\mathrm{P}(3 \mathrm{HP})$ blend by the extracellular $\mathrm{P}(3 \mathrm{HB})$-depolymerase from the bacterium strain $A$. faecalis $T 1$ was studied, and evaluation of the environmental biodegradability in the river water was comparatively carried out. The dependence of biodegradability on the phase structure and blend constituent composition was clarified.

\section{EXPERIMENTAL}

\section{Materials and Preparation of the Blends}

Bacterial polyester $\mathrm{P}(3 \mathrm{HB})$ purchased from Aldrich (Lot no. 00925KF) was purified with chloroform and $n$-hexane prior to use $\left(M_{n}: 2.13 \times 10^{5} ; M_{w} / M_{n}: 1.52\right)$. Poly $(\beta$-propiolactone) $[\mathrm{P}(3 \mathrm{HP})]$ was supplied by Tokuyama Co. (Tsukuba, Japan), which was chemically synthesized through a ring-opening polymerization method. It was also purified with the same procedure as that for $\mathrm{P}(3 \mathrm{HB})\left(M_{n}: 1.54 \times 10^{5} ; M_{w} / M_{n}: 2.32\right)$. The film samples of homopolymer $\mathrm{P}(3 \mathrm{HB}), \mathrm{P}(3 \mathrm{HP})$, and blends were prepared by the conventional solvent $\left(\mathrm{CHCl}_{3}\right)$ casting using the glass petri-dishes as the casting surfaces (thickness: $70-90 \mu \mathrm{m}$ ), and kept under ambient temperature for more than 1 month to allow crystallization to approach equilibrium before characterization.

\section{Analytical Procedures}

Thermal analyses were conducted on a SEIKODSC220U as follows: $2-4 \mathrm{mg}$ of a sample was encapsulated into an aluminum pan, and then heated from -80 to $195^{\circ} \mathrm{C}$ at a scanning rate of $10^{\circ} \mathrm{C} \mathrm{min}^{-1}$ (first heating scan). After an isothermal melting at $195^{\circ} \mathrm{C}$ for $2 \mathrm{~min}$, the sample was rapidly quenched to $-100^{\circ} \mathrm{C}$, and re-heated from -100 to $195^{\circ} \mathrm{C}$ at a scanning rate of $20^{\circ} \mathrm{C} \mathrm{min}^{-1}$ (second heating scan). Melting points $T_{\mathrm{m}}$ (1st) were taken as endothermic peak tops in the thermal diagrams recorded by the first heating scan, and heat of fusion $\Delta H_{\mathrm{m}}$ (1st) was estimated as the integral of the endothermic curves. Glass transition temperatures $T_{\mathrm{g}}$ (2nd) were evaluated as midpoints of the heat capacity change in the DSC traces recorded by the second heating scan. Cold crystallization temperatures $T_{\text {cc }}(2 \mathrm{nd})$ and $T_{\mathrm{m}}$ (2nd) were taken as respective exothermic and endothermic peak tops presented in the thermograms by the second heating scan.

An Olympus BX90 polarized optical microscopy equipped with a Mettler FP82HT hot stage and video recorder was utilized to monitor the spherulitic growth behavior. The sizes of spherulites were recorded at a given crystallization temperature $\left(T_{\mathrm{c}}\right)$, and real dimensions were calibrated with a micrometric reticule. Spherulitic growth rate was derived from the slope of $R-t$ plot, in which $R$ means the radius of spherulite at evolution time $t$.

The wide angle X-ray diffraction patterns (WAXD) were examined on a Rigaku RU-200 $(50 \mathrm{kV} / 180 \mathrm{~mA})$ and Rigaku IP R-AXIS-DS3 diffractometer. Nickelfiltered $\mathrm{Cu}-K_{\alpha} \mathrm{X}$-ray beams with a pinhole graphite monochrometer $(\lambda=0.1542 \mathrm{~nm})$ were used as the incident source. WAXD patterns were exmained with $2 \theta$ angle ranging from 6 to $40^{\circ}$ at a scanning rate of $1^{\circ} \mathrm{min}^{-1}$, and thereafter corrected to remove air scattering.

Dynamic mechanical spectra were recorded on a
SEIKO-DMS210 instrument in the tensile mode. The test samples prepared via solvent casting (length: $30 \mathrm{~mm}$; width: about $5 \mathrm{~mm}$; thickness: $70-90 \mu \mathrm{m}$ ) were measured from -75 to $160^{\circ} \mathrm{C}$ at a thermal scanning rate of $2^{\circ} \mathrm{Cmin}^{-1}$ at 0.1 and $5.0 \mathrm{~Hz}$. The peak observed in the loss tangent $v s$. temperature plot is associated with the $\alpha$-transition or glass transition in the amorphous regions.

A JEOL GSX270 NMR (67.8 MHz for ${ }^{13} \mathrm{C}$ nucleus) spectrometer was used to measure the high-resolution solid state ${ }^{13} \mathrm{C}$ NMR spectra of the blends as well as two constituent homopolymers $\mathrm{P}(3 \mathrm{HB})$ and $\mathrm{P}(3 \mathrm{HP})$. The NMR samples were packed into a zirconia rotor with a polyimide cap, and the spectra were measured at the ambient temperature with $4 \mathrm{~K}$ data points and 512-1024 accumulations under high-power proton dipolar-decoupling ( $c a .53 .1 \mathrm{kHz}$ ). Pulse repetition time was generally set at $5.0 \mathrm{~s}$, and the magic angle spinning (MAS) rate was optimized at $4.1-4.2 \mathrm{kHz} .{ }^{1} \mathrm{H}-{ }^{13} \mathrm{C}$ cross-polarization (CP) time was minimized to $0.1 \mathrm{~ms}$ to alleviate the interfering effect of $\mathrm{CP}$ relaxation on the proton spin diffusion measurements. CP mixing time equal to $2 \mathrm{~ms}$ was applied to $\mathrm{CP} / \mathrm{MAS}$ experiments. Proton spindiffusion times in laboratory frame $\left(T_{1}^{\mathrm{H}}\right)$ and rotating frame $\left(T_{1 \rho}^{\mathrm{H}}\right)$ were investigated by inversion-recovery $(\pi-\tau-\pi / 2)$ and spin-lock- $\tau$ pulse sequences, respectively. ${ }^{25}$ ${ }^{13} \mathrm{C}$ NMR chemical shifts were referred to the $\mathrm{CH}_{3}$ resonance of hexamethylbenzene (HMB) as the external standard (17.4 ppm from tetramethylsilane (TMS)).

Extracellular P(3HB)-depolymerase was purified and assayed as reported by Shirakura et $a .^{26}$ and Kasuya et al. $^{22}$ after cultivating the bacterium strain $A$. faecalis $T 1$ with $\mathrm{P}(3 \mathrm{HB})$ granules as the sole carbon source. The final protein concentration of enzyme after purification was $508 \mu \mathrm{g} \mathrm{ml}^{-1}$, and activity was estimated as 314 units $\mathrm{mg}^{-1}$. Enzymatic degradation was started by adding an aliquot of $2.0 \mu \mathrm{l}$ enzyme solution into a small bottle containing $1 \mathrm{ml}$ of potassium phosphate buffer $(\mathrm{pH}$ $7.5,37^{\circ} \mathrm{C}$ ) and a film sample (area: $1 \mathrm{~cm} \times 1 \mathrm{~cm}$; initial weight: $7-10 \mathrm{mg}$ ) under gentle reciprocal shaking. Enzymatical degradability was evaluated in triplicate as the weight loss of film for $5 \mathrm{~h}$ after the enzymatical erosion.

Measurements of aerobic environmental biodegradation in river water were carried out on a TAITEC BOD tester at $25^{\circ} \mathrm{C}$ under stirring. A sample with the same dimensions as used for the enzymatic degradation was inserted into a biochemical oxygen demand (BOD) reactor including $200 \mathrm{ml}$ river water taken from the Tamagawa river ( Tokyo, Japan) after filtration (core size of filter: $120-160 \mu \mathrm{m}$ ) and $0.2 \mathrm{ml}$ of mineral solution as reported by Abe et al. ${ }^{27}$ Biodegradability of the investigated films of homopolymers and blends was evaluated in triplicate as recorded biochemical oxygen demand subtracted by the average values of the controlled-blanks over the theoretical biochemical oxygen demand on the assumption that the total amount of carbon atoms in the polymer is entirely converted into carbon dioxide. 


\section{RESULTS AND DISCUSSION}

\section{Thermal and Crystallization Behavior of $P(3 H B) / P(3 H P)$ Blends}

Figure 1 shows the DSC traces of homopolymer $\mathrm{P}(3 \mathrm{HB}), \mathrm{P}(3 \mathrm{HP})$, and blends with various constituent compositions recorded by the first heating scan. $\mathrm{P}(3 \mathrm{HB})$ and $\mathrm{P}(3 \mathrm{HP})$ components in the blends exhibit distinct endothermic peaks, respectively, corresponding to those of the pure homopolymers despite variation in blend composition. Melting peaks appearing around 70 and $170^{\circ} \mathrm{C}$ originated from the individual constituents $\mathrm{P}(3 \mathrm{HP})$ and $\mathrm{P}(3 \mathrm{HB})$. The multiple melting features can be interpreted by several factors as distribution of lamellar thickness, modification of crystals, perfectness of crystallites and re-crystallization during the heating scan as reported by Pearce et $a l^{28}$ Melting point of the crystalline constituent in a compatible binary blend is lowered due to the mutual interaction arisen from the

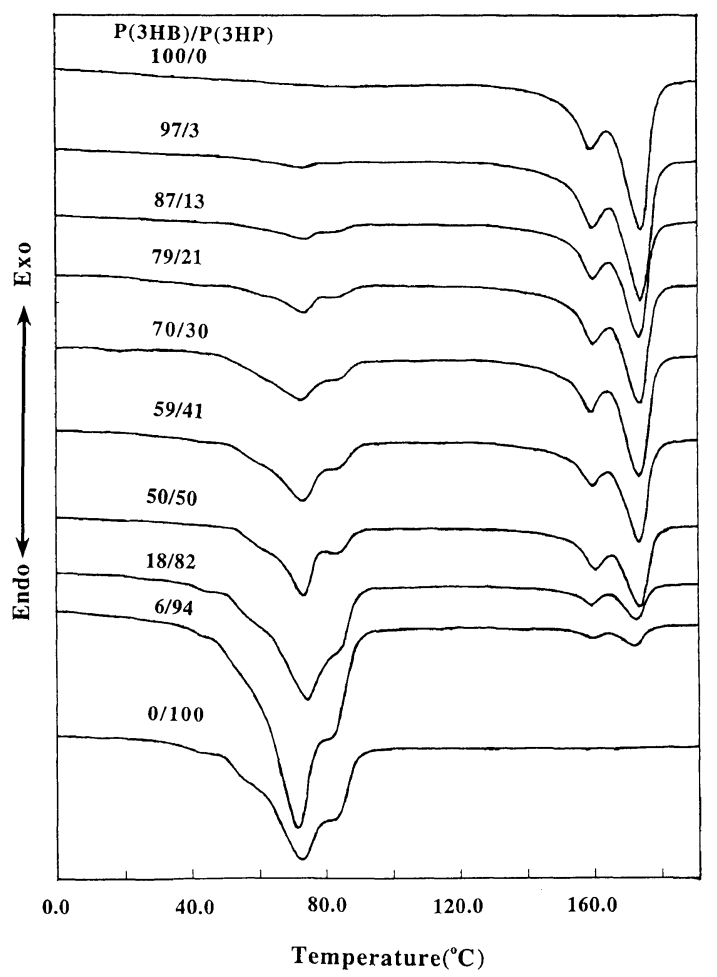

Figure 1. DSC thermograms of pure polymers $\mathrm{P}(3 \mathrm{HB}), \mathrm{P}(3 \mathrm{HP})$, and binary $\mathrm{P}(3 \mathrm{HB}) / \mathrm{P}(3 \mathrm{HP})$ blends recorded by the first heating scan. presence of a secondary amorphous partner. However, this behavior of a binary blend comprised of two semi-crystalline components may become more complicated..$^{13}$ For $\mathrm{P}(3 \mathrm{HB}) / \mathrm{P}(3 \mathrm{HP})$ blends prepared via solvent casting, the melting points $T_{\mathrm{m}}$ (1st) and heat of fusion $\Delta H$ (1st) are summarized in Table $\mathrm{I}$, indicating no appreciable change in the melting point within instrumental error for each component polymer. The heat of fusion of each constituent seems to be linear with weight contribution in the blend (not shown here). In a view of this result, no specific intermolecular interaction in this blend system can be demonstrated.

DSC thermograms measured by the second heating scan are depicted in Figure 2. Glass transition temperatures $\left(T_{\mathrm{g}}\right)$ are summarized in Table I. Examining $T_{\mathrm{g}}$, two glass transition temperatures equal to those of pure $\mathrm{P}(3 \mathrm{HP})$ and $\mathrm{P}(3 \mathrm{HB})$ are observed on the whole range of blend composition. Hence, melt-immiscibility of these two constituents on a scale $(10 \mathrm{~nm})^{29}$ of DSC can be concluded. The multiple melting features observed in the thermograms by the first heating scans virtually disappear in Figure 2. The origin of the multiple-melting feature presented thus probably stems from the thermal history during solvent casting. Different densities of the polymer coils in the solution state lead to more complicated distribution of the lamellar thickness than that in the case of melt casting, resulting in a multiple melting behavior expected according to the GibbsThompson description, ${ }^{30}$

$$
T_{\mathrm{m}}(\text { obsv. })=T_{\mathrm{m}}^{\mathrm{o}}\left[1-\frac{2 \sigma_{e}}{\left(\Delta H_{\mathrm{f}}\right) \cdot L}\right]
$$

where $T_{\mathrm{m}}$ (obsv.) and $T_{\mathrm{m}}^{\mathrm{o}}$ express the observed and equilibrium melting points, respectively; $\sigma_{e}, \Delta H_{\mathrm{f}}$ and $L$ mean the surface free energy, heat of fusion and lamellar thickness of the crystallite, respectively. From cold crystallization temperature, increase in the weight fraction of the secondary component results in a higher $T_{\mathrm{cc}}(2 \mathrm{nd})$, and this is more obvious for the $\mathrm{P}(3 \mathrm{HP})$ component. If the building-structures of $\mathrm{P}(3 \mathrm{HB})$ and $\mathrm{P}(3 \mathrm{HP})$ are considered, the chain flexibility of $\mathrm{P}(3 \mathrm{HB})$ is expected to be lower due to steric hindrance of the side chain as confirmed by $T_{\mathrm{g}}$.

Figure 3 depicts spherulitic growth $G(t)$ of $\mathrm{P}(3 \mathrm{HB})$ presented as either the pure state or a component of the binary blend at various isothermal crystallization

Table I. Thermal characteristics of homopolymers $\mathrm{P}(3 \mathrm{HB})$ and $\mathrm{P}(3 \mathrm{HP})$ and binary blends

\begin{tabular}{|c|c|c|c|c|c|c|c|c|c|c|}
\hline \multirow{2}{*}{$\begin{array}{c}\text { Blend } \\
\mathrm{P}(3 \mathrm{HB}) / \mathrm{P}(3 \mathrm{HP})\end{array}$} & \multicolumn{2}{|c|}{$T_{\mathrm{m}} /{ }^{\circ} \mathrm{C}(1 \mathrm{st})^{\mathrm{a}}$} & \multicolumn{2}{|c|}{$\Delta H / \mathrm{Jg}^{-1}(1 \mathrm{st})^{\mathrm{a}}$} & \multicolumn{2}{|c|}{$T_{\mathrm{g}}{ }^{10} \mathrm{C}(2 \mathrm{nd})^{\mathrm{a}}$} & \multicolumn{2}{|c|}{$T_{\mathrm{cc}} /{ }^{\circ} \mathrm{C}(2 \mathrm{nd})^{\mathrm{a}}$} & \multicolumn{2}{|c|}{$T_{\mathrm{m}} /{ }^{\circ} \mathrm{C}(2 \mathrm{nd})^{\mathrm{a}}$} \\
\hline & $\mathrm{P}(3 \mathrm{HB})$ & $\mathrm{P}(3 \mathrm{HP})$ & $\mathrm{P}(3 \mathrm{HB})$ & $\mathbf{P}(3 \mathrm{HP})$ & $\mathrm{P}(3 \mathrm{HB})$ & $\mathbf{P}(3 \mathrm{HP})$ & $\mathrm{P}(3 \mathrm{HB})$ & $\mathrm{P}(3 \mathrm{HP})$ & $\mathrm{P}(3 \mathrm{HB})$ & $(3 \mathrm{HP})$ \\
\hline $100 / 0$ & $159.3(173.9)$ & - & 85.7 & - & 0.9 & - & 49.2 & - & 172.2 & - \\
\hline $93 / 07$ & $159.5(174.2)$ & 72.8 & 83.9 & 2.5 & 1.2 & -19.3 & 49.8 & n.d. ${ }^{b}$ & 172.1 & 78.1 \\
\hline $87 / 13$ & $159.5(173.5)$ & 73.6 & 71.6 & 14.1 & 0.8 & -23.0 & 48.2 & n.d. & 172.1 & 78.1 \\
\hline $79 / 21$ & 159.9 (173.6) & 73.9 & 67.5 & 17.5 & 0.8 & -19.3 & 49.4 & 19.2 & 172.5 & 77.4 \\
\hline $70 / 30$ & $159.0(173.7)$ & 73.3 & 56.2 & 32.1 & 0.9 & -22.3 & 48.3 & n.d. & 172.1 & 76.6 \\
\hline $59 / 41$ & 159.7 (173.4) & 73.6 & 46.3 & 36.8 & 0.4 & -21.3 & 49.7 & 16.9 & 172.2 & 75.5 \\
\hline $50 / 50$ & 160.3 (173.6) & 73.4 & 43.8 & 39.0 & 1.5 & -19.9 & 50.3 & 16.8 & 171.9 & 75.7 \\
\hline $18 / 82$ & $158.8(172.6)$ & 74.5 & 15.9 & 70.3 & n.d. & -20.7 & 51.5 & 15.8 & 171.4 & 75.2 \\
\hline $06 / 94$ & 158.7 (171.9) & 71.6 & 5.3 & 87.6 & n.d. & -23.1 & n.d & 14.3 & 170.4 & 73.2 \\
\hline $0 / 100$ & - & 72.9 & - & 90.5 & - & -23.2 & - & 11.7 & - & 72.7 \\
\hline
\end{tabular}

${ }^{\mathrm{a}} 1$ st and 2 nd indicate the data measured by the first and the second DSC heating scans, respectively. ${ }^{\mathrm{b}}$ n.d.: not detected. 


\section{A. CAO et al.}

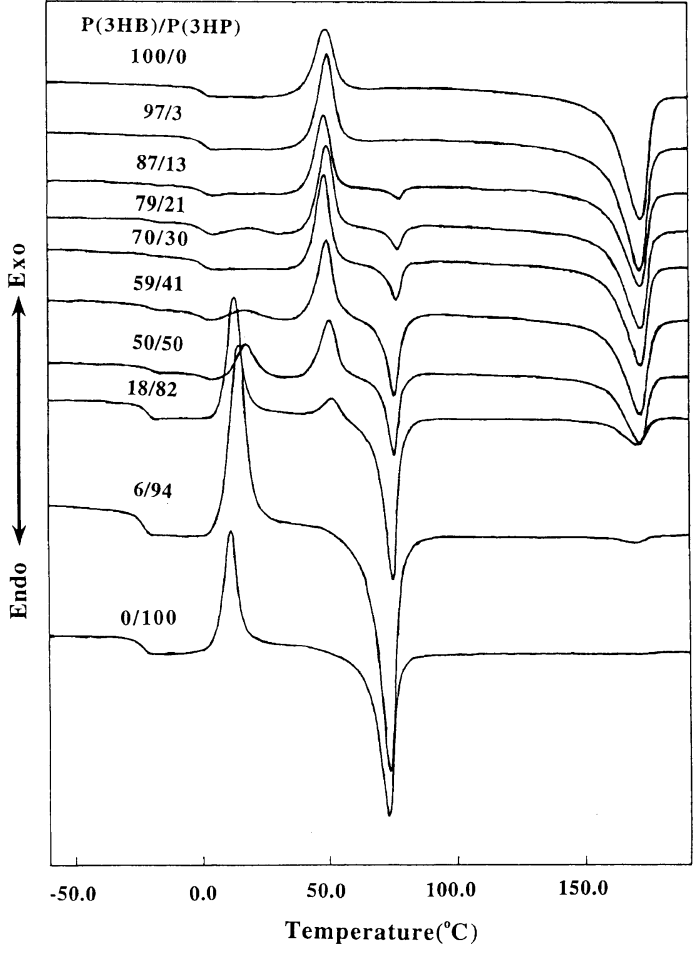

Figure 2. DSC thermograms of the pure polymers $\mathrm{P}(3 \mathrm{HB}), \mathrm{P}(3 \mathrm{HP})$, and binary $\mathrm{P}(3 \mathrm{HB}) / \mathrm{P}(3 \mathrm{HP})$ blends measured by the second heating scan. temperatures. Increasing the weight fraction of $\mathrm{P}(3 \mathrm{HP})$ from 0 to $50 \%$, only slight difference in the apparent spherulitic growth rate is observed. $T_{\mathrm{c} \text { max }}$, the crystallization temperature at which the maximum $G(t)$ can be detected, is approximately independent of the amount of $\mathrm{P}(3 \mathrm{HP})$ constituent. Hence, in the case of blend, slight decrease in the spherulitic growth of $\mathrm{P}(3 \mathrm{HB})$ can be reasonably accounted for the dilution effect of $\mathrm{P}(3 \mathrm{HP})$ melt on the $\mathrm{P}(3 \mathrm{HB})$ crystallization front. The spherulitic

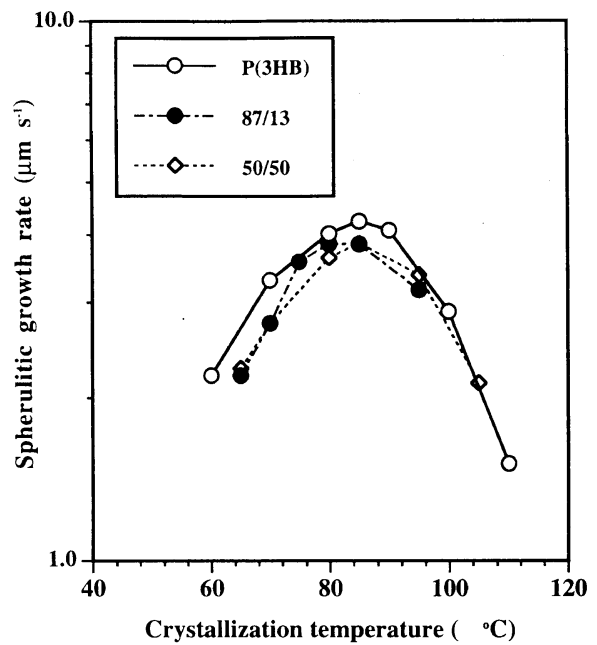

Figure 3. Spherulitic growth rate of $\mathrm{P}(3 \mathrm{HB})$ in pure and blending states.
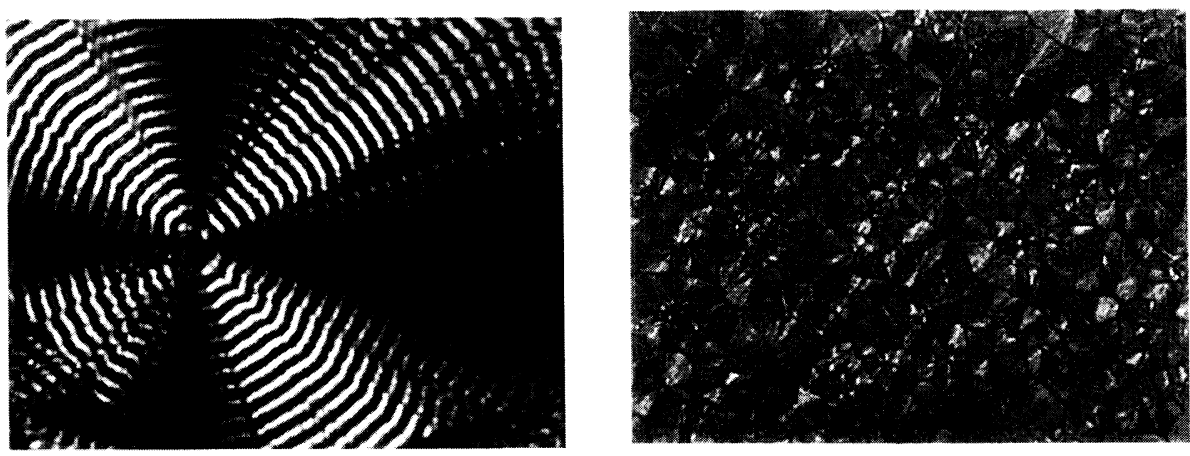

$\mathbf{P}(\mathbf{3 H B})$

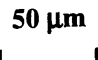

P(3HP)
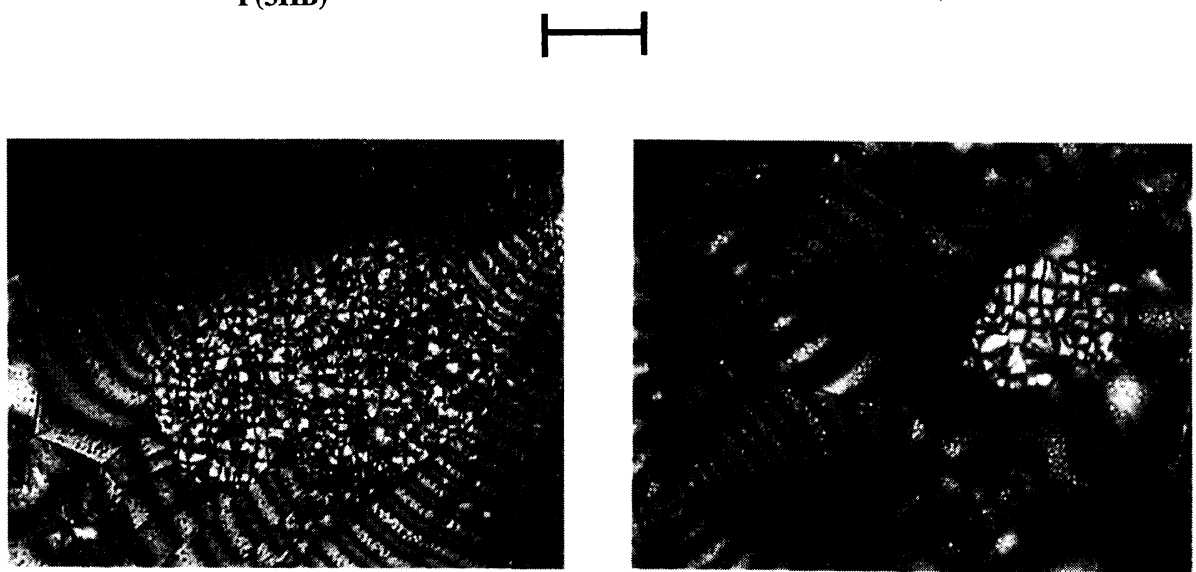

$\mathbf{P}(\mathbf{3 H B}) / \mathbf{P}(3 \mathrm{HP})$ 50/50

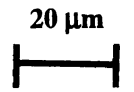

$\mathbf{P}(\mathbf{3 H B}) / \mathbf{P}(\mathbf{3 H P})$ 50/50

Figure 4. Spherulitic morphologies of pure polymers $\mathrm{P}(3 \mathrm{HB}), \mathrm{P}(3 \mathrm{HP})$, and representative $50 / 50$ blend at an isothermal crystallization temperature of $60^{\circ} \mathrm{C}$. 

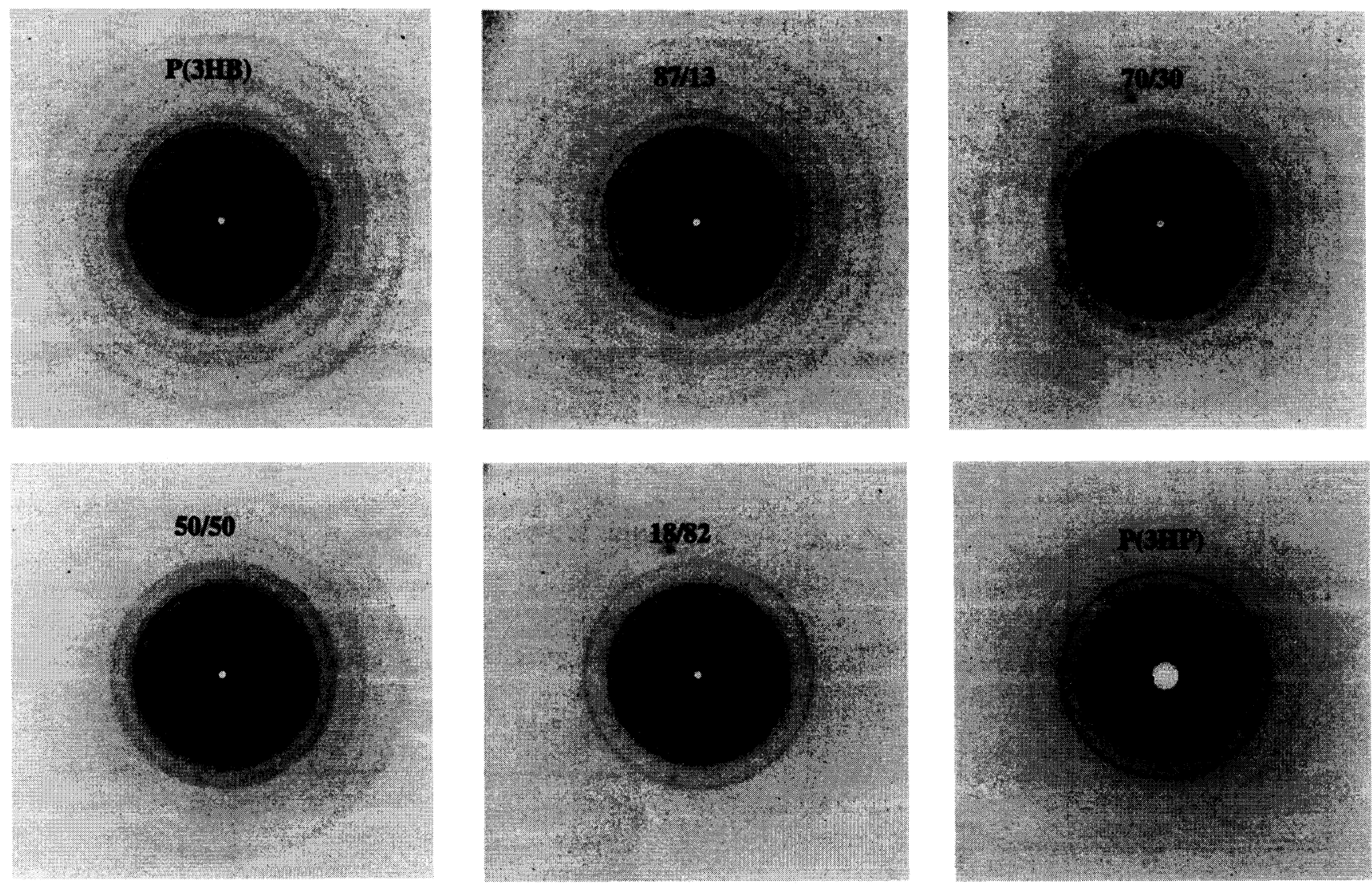

Figure 5. Wide angle X-ray diffraction patterns for $\mathrm{P}(3 \mathrm{HB}), \mathrm{P}(3 \mathrm{HP})$, and blends of $\mathrm{P}(3 \mathrm{HB}) / \mathrm{P}(3 \mathrm{HP})=87 / 13,70 / 30,50 / 50$, and $18 / 82$.

growth of $\mathrm{P}(3 \mathrm{HP})$ in the pure or blending state could not be precisely estimated due to the rapid nucleation, resulting in quick impingement of spherulites within a minute even at a supercooling $\left(T_{\mathrm{m}}-T_{\mathrm{c}}\right)$ of about $7-10^{\circ} \mathrm{C}$.

The photographs presented in Figure 4 express the morphology of the pure polymer $\mathrm{P}(3 \mathrm{HB}), \mathrm{P}(3 \mathrm{HP})$ as well as a $50 / 50$ blend recorded at a given crystallization temperature of $60^{\circ} \mathrm{C}$. The average dimension of $\mathrm{P}(3 \mathrm{HP})$ spherulites after impingement was about $20 \mu \mathrm{m}$, which is 2 order in magnitude smaller than that of $\mathrm{P}(3 \mathrm{HB})$ spherulites. In a previous work, ${ }^{8}$ bacterial copolyester $\mathrm{P}(3 \mathrm{HB}-\mathrm{co}-95.9 \mathrm{~mol} \% 3 \mathrm{HP})$ formed micro-crystals similar to those of the chemosynthetic homopolymer $\mathrm{P}(3 \mathrm{HP})$. Hence, morphology in Figure 4 virtually represents the true $\mathrm{P}(3 \mathrm{HP})$ type of spherulites. In the case of blend, two photographs of 50/50 blend in Figure 4 (below) indicate micro-crystals of $\mathrm{P}(3 \mathrm{HP})$ with dimensions much less than those in the pure polymer are interestingly observed to be occluded in the region of intra- and/or inter-spherulite of $\mathrm{P}(3 \mathrm{HB})$.

\section{Wide-Angle $X$-Ray Diffraction of the $P(3 H B) / P(3 H P)$ Blends}

Figures 5 show the wide angle $\mathrm{X}$-ray diffraction patterns of homopolymers $\mathrm{P}(3 \mathrm{HB}), \mathrm{P}(3 \mathrm{HP})$ as well as binary blends with various constituent compositions. The observed X-ray diffraction patterns of blends depicted in Figure 5 seem to be superimpositions of those of the individual pure polymers $\mathrm{P}(3 \mathrm{HB})$ and $\mathrm{P}(3 \mathrm{HP})$. The diffraction features of $\mathrm{P}(3 \mathrm{HB})$ in the pure or blending state in Figure 6 indicate pure and component $\mathrm{P}(3 \mathrm{HB})$ share the same typical orthorhombic left-handed $22_{1}$ helix crystalline structure with the crystallographic parameters $(a=5.76 \AA ; b=13.20 \AA ; c=5.96 \AA)$ as elucidated by Okamura et al. ${ }^{31}$ The X-ray diffraction in Figure 6 also confirms that the component $\mathrm{P}(3 \mathrm{HP})$ forms the same left-handed $2{ }_{1}$-helix packing structure with the $c$-axial period of $7.02 \AA\left(2 \theta=25.4^{\circ}\right)$ as that in the pure state. Wasai et al. $^{32}$ and Yamashita et al. ${ }^{24}$ reported that $\mathrm{P}(3 \mathrm{HP})$ has respective $2{ }_{1}$ helix and planar-zigzag packing structures. The former is more stable. Inspecting the resultant X-ray diffraction patterns, it can be demonstrated that the $\mathrm{P}(3 \mathrm{HP})$ constituent forms the more stable crystalline structure over the whole blend composition regardless of disturbance of the secondary component $\mathrm{P}(3 \mathrm{HB})$.

\section{Dynamic Mechanical Thermal Analyses}

Dynamic mechanical relaxation is extremely sensitive to the sizes of domains in the blends. ${ }^{19,33}$ Figure 7 depicts the DMTA results of two pure polyesters and the representative $50 / 50$ blend. Elastic modulus (storage modulus) of $50 / 50$ blend drastically increased in comparison with the pure polymer $\mathrm{P}(3 \mathrm{HP})$. Furthermore, Figure 8 expresses the loss tangent, in which the observed peaks are theoretically associated with the $\alpha$-transition. In contrast, glass transition temperature $T_{\mathrm{g}}$ of the pure polymers derived from the peak tops in Figure 8 are about $20^{\circ} \mathrm{C}$ higher than those values by DSC, and the frequency-dependence of $T_{\mathrm{g}}$ was confirmed. Substantially broader temperature ranges of $\alpha$-transition, about $-30-40^{\circ} \mathrm{C}$ for $\mathrm{P}(3 \mathrm{HB})$ and $-60-10^{\circ} \mathrm{C}$ for $\mathrm{P}(3 \mathrm{HP})$, are observed in Figure 8. Inspecting Figure 8, DMTA 


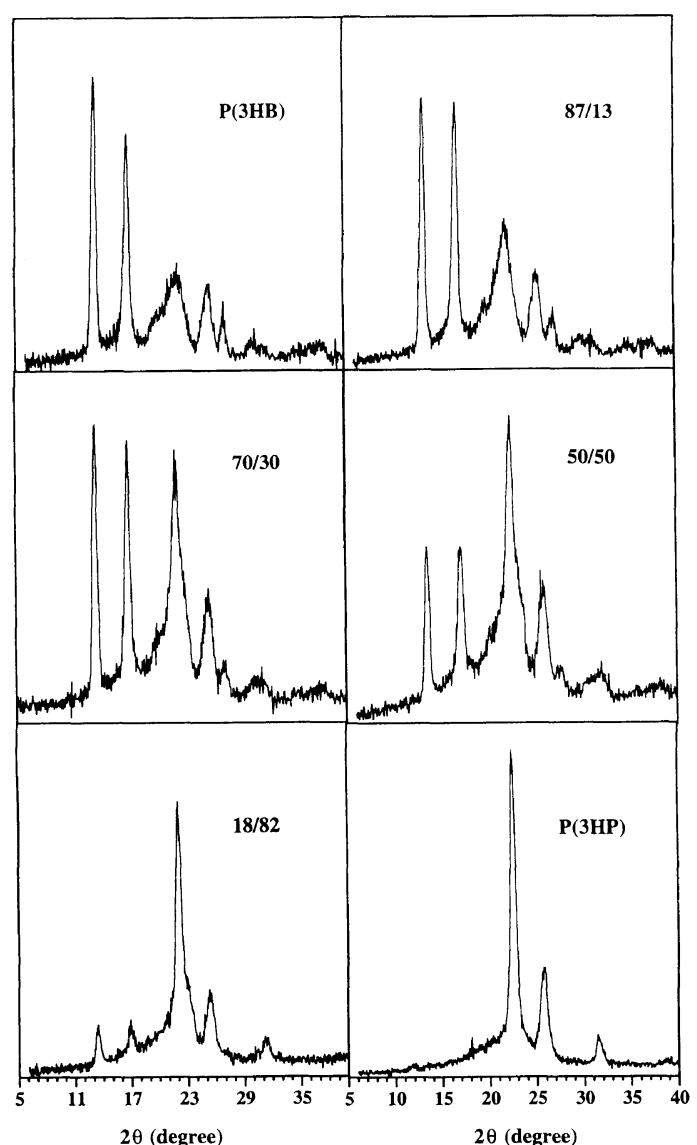

Figure 6. Wide angle $\mathrm{X}$-ray diffraction intensity $v s .2 \theta$ degree for $\mathrm{P}(3 \mathrm{HB}), \mathrm{P}(3 \mathrm{HP})$, and blends of $\mathrm{P}(3 \mathrm{HB}) / \mathrm{P}(3 \mathrm{HP})=87 / 13,70 / 30,50 / 50$, and $18 / 82$.

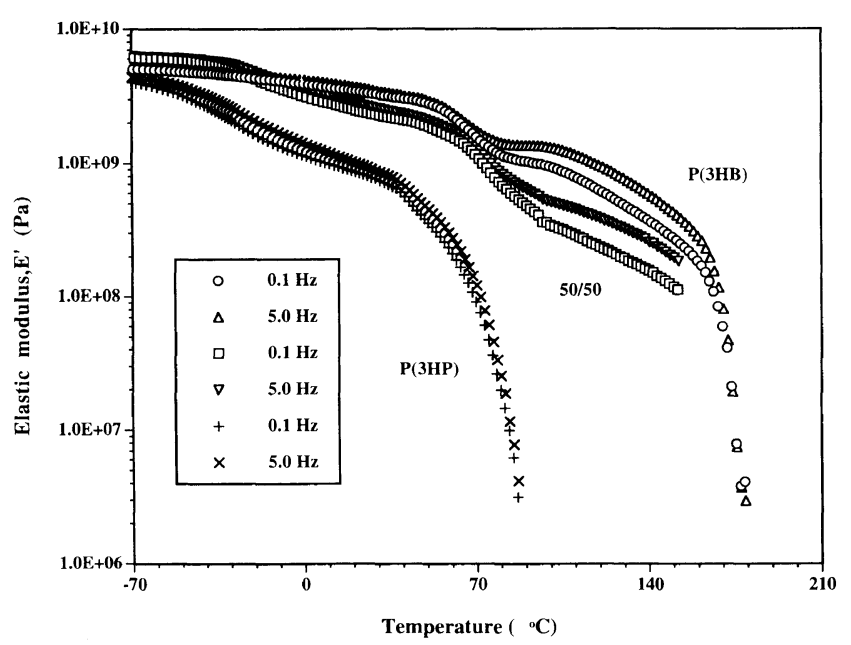

Figure 7. Dynamic mechanical thermal behavior for pure polymers $\mathrm{P}(3 \mathrm{HB}), \mathrm{P}(3 \mathrm{HP})$, and $50 / 50$ blend.

recorded at $5.0 \mathrm{~Hz}$ exhibits a much broader $\alpha$-transition in the case of $50 / 50$ blend, and its lineshape is more reasonably considered to consist of two individual contributions pertaining to those of homopolymers $\mathrm{P}(3 \mathrm{HB})$ and $\mathrm{P}(3 \mathrm{HP})$. Therefore, immiscible properties of the $\mathrm{P}(3 \mathrm{HB}) / \mathrm{P}(3 \mathrm{HP})$ blends on an DMTA observation scale (about $10 \mathrm{~nm}$ ) can be concluded.

Proton Diffusion of the $P(3 H B) / P(3 H P)$ Blends

High-resolution solid state ${ }^{13} \mathrm{C}$ NMR measurements

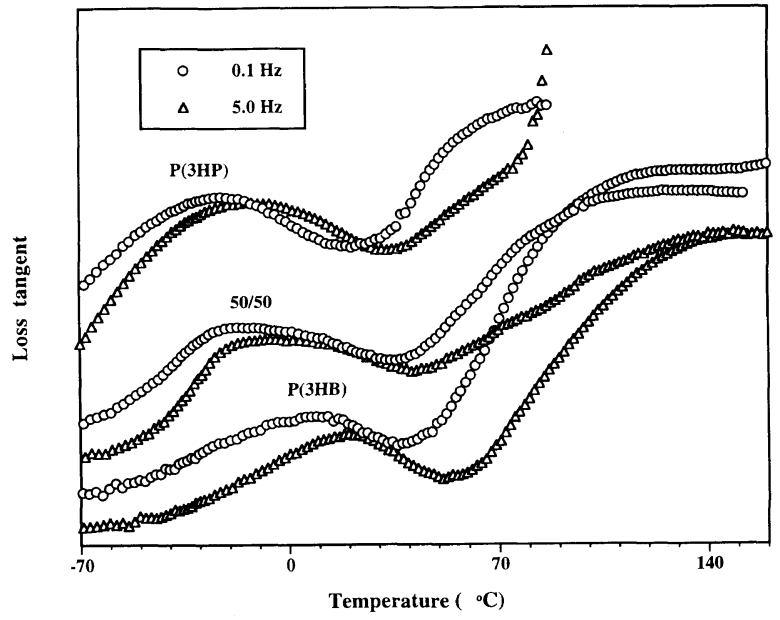

Figure 8. Loss tangent as a function of temperature for pure polymers $\mathrm{P}(3 \mathrm{HB}), \mathrm{P}(3 \mathrm{HP})$, and $50 / 50$ blend.

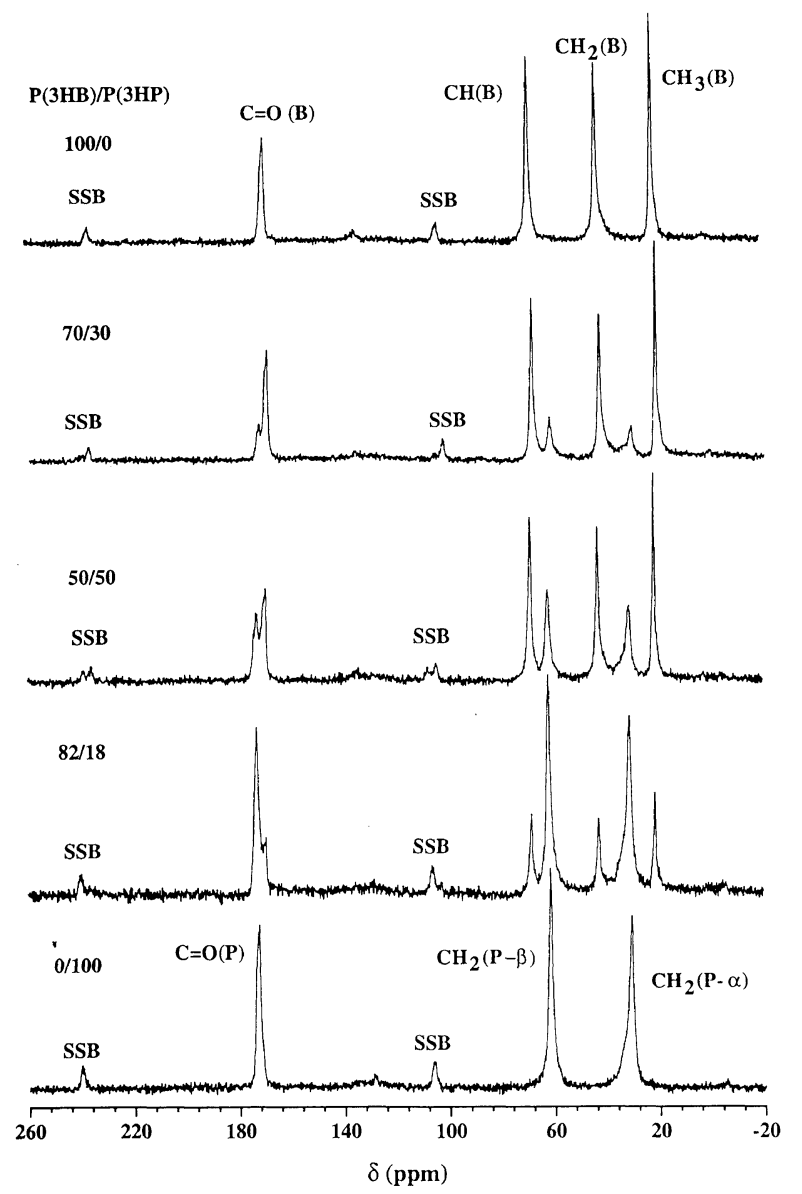

Figure 9. $67.8 \mathrm{MHz}{ }^{13} \mathrm{C} \mathrm{CP} / \mathrm{MAS}$ NMR spectra for homopolymers $\mathrm{P}(3 \mathrm{HB}), \mathrm{P}(3 \mathrm{HP})$, and binary blends.

were carried out to characterize the solid structures of the $\mathrm{P}(3 \mathrm{HB}) / \mathrm{P}(3 \mathrm{HP})$ blends. Figure 9 shows the conventional $\mathrm{CP} / \mathrm{MAS}{ }^{13} \mathrm{C}$ NMR spectra of the investigated samples. Viewing the resonances of carbonyl, the splits can be assigned to the origins of $\mathrm{P}(3 \mathrm{HP})$ and $\mathrm{P}(3 \mathrm{HB})$, respectively around 171 and $169 \mathrm{ppm}$.

Monitoring proton diffusion behavior has been proved effective for analyzing domain sizes of the separated phases in polymer blends. ${ }^{25,34-37}$ Figure 10 depicts the stacked ${ }^{13} \mathrm{C}$ NMR spectra of the $50 / 50$ blend as a function of time delay $\tau$ after a $\pi$-pulse in the inversion-recovery 


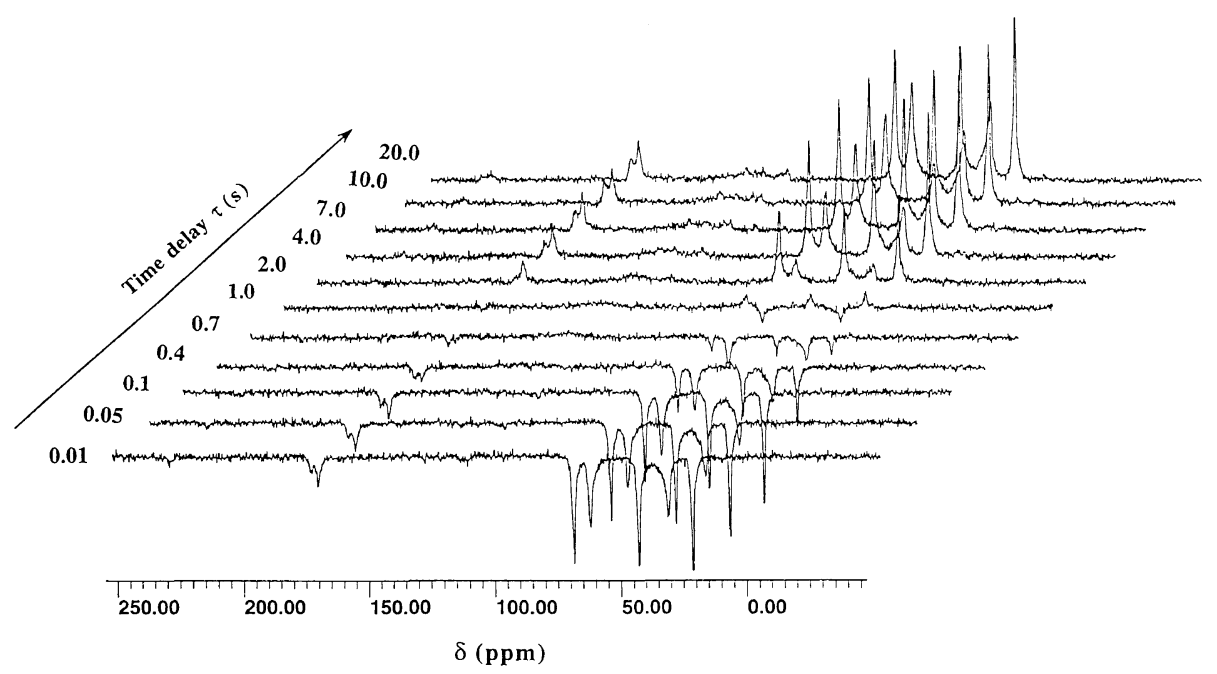

Figure 10. The stacked $67.8 \mathrm{MHz}{ }^{13} \mathrm{C}$ NMR spectra for the $50 / 50 \mathrm{P}(3 \mathrm{HB}) / \mathrm{P}(3 \mathrm{HP})$ blend recorded by the inversion-recovery pulse sequence.

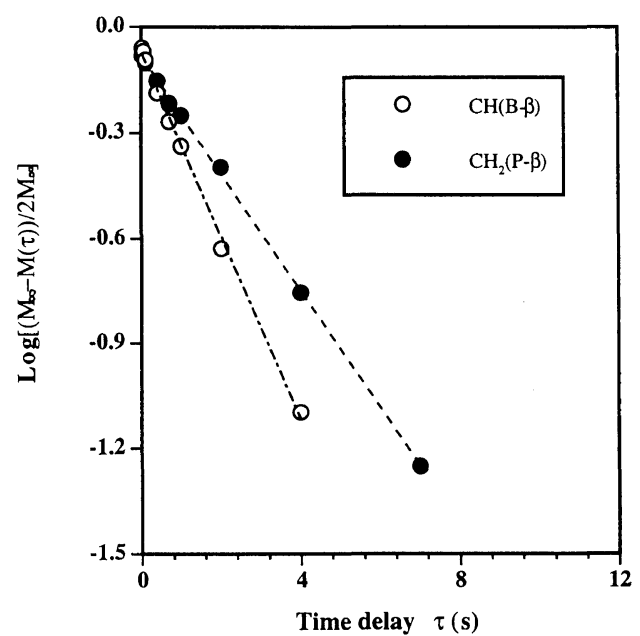

Figure 11. Logarithmic plot of ${ }^{13} \mathrm{C}$ resonance intensity $v s$. time delay for the $50 / 50 \mathrm{P}(3 \mathrm{HB}) / \mathrm{P}(3 \mathrm{HP})$ blend to measure $T_{1}^{\mathrm{H}}$.

sequence. In principle, the apparent ${ }^{13} \mathrm{C}$ magnetization at each specific site is indirectly associated with proton magnetization locked in the ${ }^{1} \mathrm{H}$ channel through cross polarization under the matched Hartmann-Hahn condition, and decays in a manner mathematically described as

$$
M(\tau)=M_{\infty}\left[1-2 \exp \left(-\tau / T_{1}^{\mathrm{H}}\right)\right]
$$

in which $M(\tau)$ and $M_{\infty}$ represent the carbon resonance intensities at a given time delay $\tau$ and equilibrium state $\left(\tau>5 T_{1}^{\mathrm{H}}\right)$, respectively; $T_{1}^{\mathrm{H}}$ expresses the proton spinrelaxation time in the laboratory frame. Further, eq 2 can be rearranged as

$$
\log \left[\frac{M_{\infty}-M(\tau)}{2 M_{\infty}}\right]=-\tau T_{1}^{\mathrm{H}}
$$

Figure 11 expresses $\log \left[\left(M_{\infty}-M(\tau)\right) / 2 M_{\infty}\right]$ of the carbon resonances at $\beta$ sites of both $3 \mathrm{HB}$ and $3 \mathrm{HP}$ repeating units as a function of time delay $\tau$. Good linearity was observed, indicating a single-component $T_{1}^{\mathrm{H}}$ relaxation behavior. Therefore, spin diffusion of proton ensembles attributed to $\mathrm{P}(3 \mathrm{HB})$ or $\mathrm{P}(3 \mathrm{HP})$ was efficiently averaged out over the region on the time scale of $T_{1}^{\mathrm{H}}$, respectively. However, the difference in $T_{1}^{\mathrm{H}}$ be-
Table II. Proton spin-lattice relaxation times $\left(T_{1}^{\mathrm{H}}\right.$ and $\left.T_{1 \rho}^{\mathrm{H}}\right)$ for homopolymers

\begin{tabular}{|c|c|c|c|c|c|c|}
\hline \multirow{3}{*}{$\begin{array}{l}\text { Sample } \\
\text { code }\end{array}$} & \multicolumn{2}{|c|}{$T_{1}^{\mathrm{H}} / \mathrm{s}$} & \multicolumn{4}{|c|}{$T_{1 \rho}^{\mathrm{H}} / \mathrm{ms}$} \\
\hline & \multirow{2}{*}{$\begin{array}{c}\mathrm{CH}(\mathrm{B}) \\
3.47\end{array}$} & \multirow{2}{*}{$\frac{\mathrm{CH}_{2}(\mathrm{P}-\beta)}{-}$} & \multicolumn{2}{|c|}{$\mathrm{CH}(\mathrm{B})$} & \multicolumn{2}{|c|}{$\mathrm{CH}_{2}(\mathrm{P}-\beta)$} \\
\hline & & & 41.3 & 103.1 & & \\
\hline $70 / 30$ & 3.30 & 5.52 & 45.1 & 90.9 & 15.2 & 29.9 \\
\hline $50 / 50$ & 3.83 & 6.00 & 33.8 & 78.1 & 13.8 & 32.3 \\
\hline $18 / 82$ & 4.21 & 5.83 & 9.8 & 62.9 & 21.5 & 35.0 \\
\hline $\mathrm{P}(3 \mathrm{HP})$ & - & 3.39 & & & 14.1 & 41.2 \\
\hline
\end{tabular}
$\mathrm{P}(3 \mathrm{HB}), \mathrm{P}(3 \mathrm{HP})$ and blends

tween $\mathrm{P}(3 \mathrm{HB})$ and $\mathrm{P}(3 \mathrm{HP})$ in Table II implies that these two components in the $50 / 50$ blend were not intimately mixed, exhibiting immiscibility even on an observation scale of $c a .50 \mathrm{~nm}$ as expected in accordance to equation $^{25}$

$$
\langle r\rangle=(6 D T)^{1 / 2}
$$

in which $\langle r\rangle$ is the average diffusive path-length. $D$ is the spin diffusion coefficient, and in the common case of polymer, its typical value is about $10^{-12} \mathrm{~cm}^{2} \mathrm{~s}^{-1} . T$ represents the characteristic time of proton spin diffusion $\left(T_{1}^{\mathrm{H}}, T_{1 \rho}^{\mathrm{H}}\right)$. In general, inspecting $T_{1}^{\mathrm{H}}$ of $\mathrm{P}(3 \mathrm{HB})$ and $\mathrm{P}(3 \mathrm{HP})$ in the pure and blending states, two discriminate $T_{1}^{\mathrm{H}}$ of the constituent $\mathrm{P}(3 \mathrm{HB})$ and $\mathrm{P}(3 \mathrm{HP})$ indicate the immiscible properties of the $\mathrm{P}(3 \mathrm{HB}) / \mathrm{P}(3 \mathrm{HP})$ blends on the scale of $T_{1}^{\mathrm{H}}$. In comparison with $\mathrm{P}(3 \mathrm{HP})$ in the pure state, increase in $T_{1}^{\mathrm{H}}$ of the component $\mathrm{P}(3 \mathrm{HP})$ reflects decrease in proton spin-diffusion due to the presence of a secondary component bearing less chain-flexibility. The difference in $T_{1}^{\mathrm{H}}$ of $\mathrm{P}(3 \mathrm{HB})$ between the pure and blending states is not so significant.

For proton spin diffusion in a more shorter range of spatial proximity than that by $T_{1}^{\mathrm{H}}$, Figure 12 depicts the ${ }^{13} \mathrm{C}$ NMR spectra of the $50 / 50$ blend recorded by the $\pi / 2-\tau-\mathrm{CP}$ pulse sequence. Theoretically, the carbon resonance intensity transferred from the ${ }^{1} \mathrm{H}$ channel through the CP mixing decreases as

$$
M(\tau)=\sum_{i} M_{0 i} \exp \left(-\tau / T_{1 \rho i}^{\mathrm{H}}\right)
$$

where $M(\tau)$ and $M_{0 i}$ express ${ }^{13} \mathrm{C}$ resonance intensity at a 


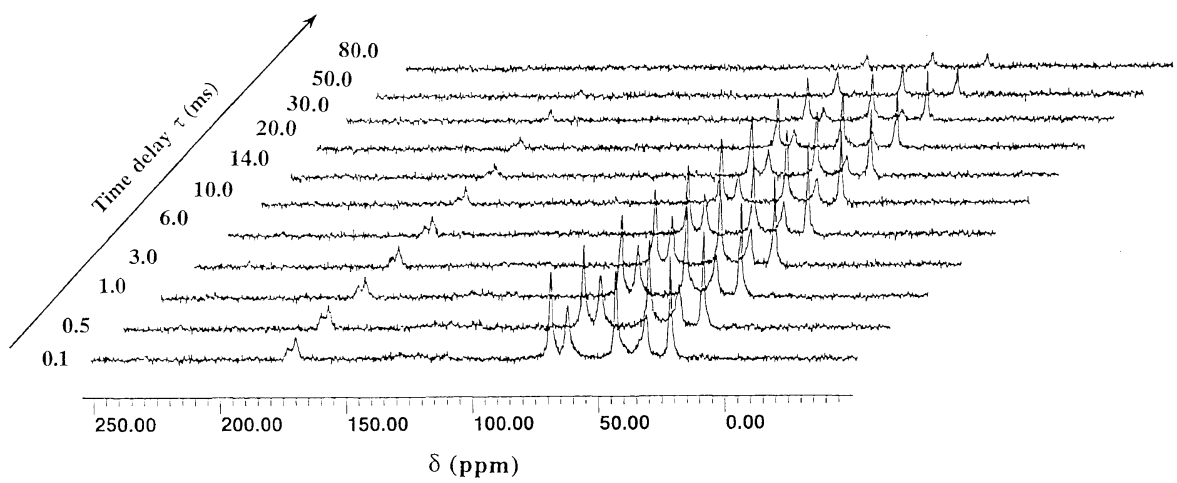

Figure 12. The stacked $67.8 \mathrm{MHz}^{13} \mathrm{C}$ NMR spectra for the $50 / 50 \mathrm{P}(3 \mathrm{HB}) / \mathrm{P}(3 \mathrm{HP})$ blend recorded by the $\pi / 2-\tau-\mathrm{CP}$ pulse sequence to measure $T_{1 \rho}^{\mathrm{H}}$.
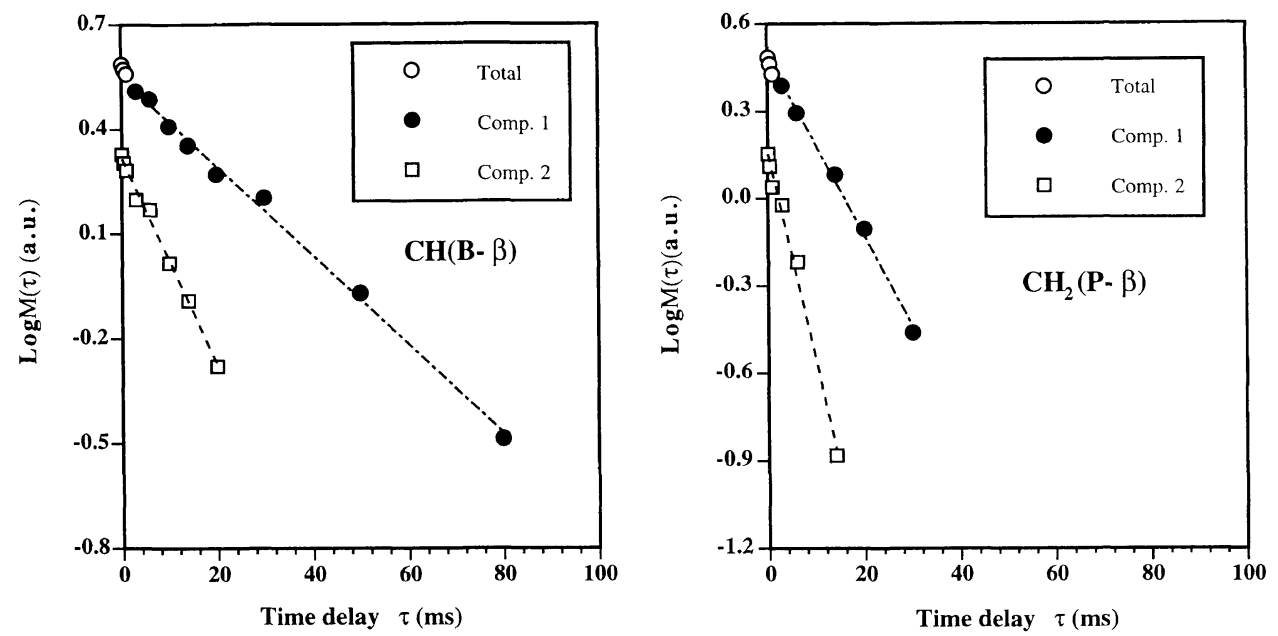

Figure 13. Logarithmic plot of ${ }^{13} \mathrm{C}$ resonance intensity $v s$. time delay for the $50 / 50 \mathrm{P}(3 \mathrm{HB}) / \mathrm{P}(3 \mathrm{HP})$ blend to measure $T_{1 \rho}^{\mathrm{H}}$.

given time delay $\tau$, and initial intensity of the relaxation component $i . T_{1 \rho i}^{\mathrm{H}}$ is the corresponding proton relaxation time in the rotating frame. In Figure $13, \log M(\tau)$ of the carbon resonances at the $\beta$ sites of individual repeating units of components $\mathrm{P}(3 \mathrm{HB})$ and $\mathrm{P}(3 \mathrm{HP})$ in the $50 / 50$ blend are plotted against time delay $\tau \cdot{ }^{13} \mathrm{C}$ magnetization decay is well in agreement with the bi-exponential model for $\mathrm{P}(3 \mathrm{HB})$ and $\mathrm{P}(3 \mathrm{HP})$, implying heterogeneous proton spin diffusion on the time scale of $T_{1 \rho}^{\mathrm{H}}$ about 1 order in the magnitude less than that by $T_{1}^{\mathrm{H}}$. Examining the $T_{1 \rho}^{\mathrm{H}}$ in Table II, the heterogeneous nature of pure polymers or components in the blends is revealed, and the longer and shorter $T_{1 \rho}^{\mathrm{H}}$ can be attributed to the crystalline and amorphous regions respectively.

\section{Assessment of Biodegradability}

Figure 14 expresses the enzymatical degradation of the binary blends by the extracellular $\mathrm{P}(3 \mathrm{HB})$ depolymerase from $A$. faecalis $T 1$. Over the whole range of blend composition, weight loss of film samples approximately increases proportionally with the weight fraction of the constituent $\mathrm{P}(3 \mathrm{HP})$. Kasuya et al. ${ }^{38}$ and Mukai et al. ${ }^{39}$ reported that the enzymatic erosion of bacterial $\mathrm{P}(3 \mathrm{HB})$ by $A$. faecalis $T 1$ depolymerase proceeds as follows, the binding sites of enzyme are adsorbed onto the more stable substrate, e.g., crystalline region with less polymer chain mobility, and the polymer chains are hydrolyzed by the active sites of catalytic domains. Considering the absorption experiment reported by Kasuya et al., ${ }^{22}$ ability of the absorption of the enzyme on the surface

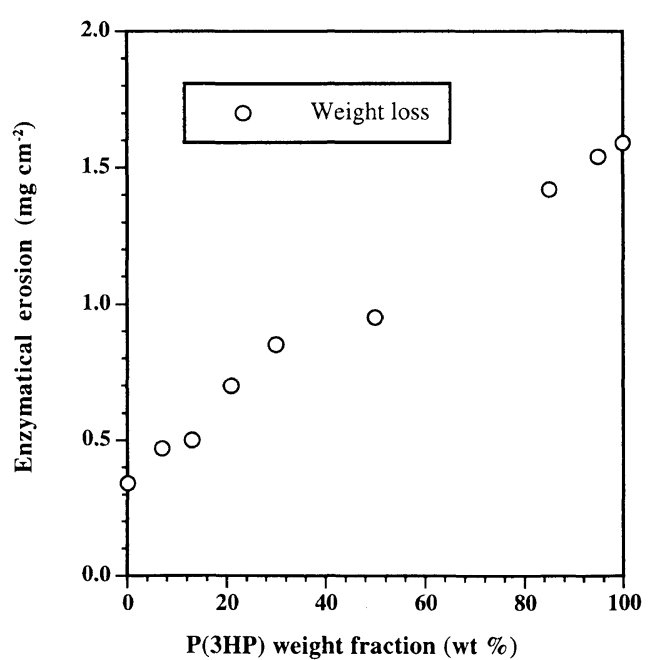

Figure 14. Biodegradation of the pure $\mathrm{P}(3 \mathrm{HB})$ and $\mathrm{P}(3 \mathrm{HP})$ polymers as well as their binary blends by the extracellular $\mathrm{P}(3 \mathrm{HB})$-depolymerase from $A$. faecalis $T 1$.

of $\mathrm{P}(3 \mathrm{HP})$ film is two times higher than that on the $\mathrm{P}(3 \mathrm{HB})$ film at a given concentration of depolymerase. Hence, the higher biodegradation rate of $\mathrm{P}(3 \mathrm{HP})$ film may be due to larger amount of adsorbed enzyme. Although the depolymerase from $A$. faecalis $T 1$ on the feedstock of $\mathrm{P}(3 \mathrm{HB})$ is an extracellular $\mathrm{P}(3 \mathrm{HB})$ depolymerase, biodegradation demonstrates that $\mathrm{P}(3 \mathrm{HP})$ is the analogue of $\mathrm{P}(3 \mathrm{HB})$ type of the substrate. Biodegradation of the binary blend exhibited a feature as the 


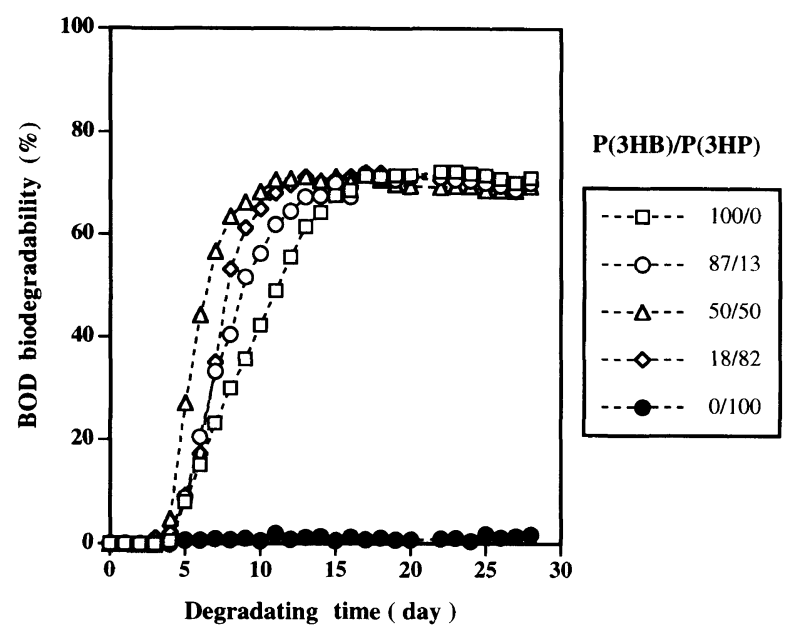

Figure 15. Environmental biodegradation of the pure $\mathrm{P}(3 \mathrm{HB})$ and $\mathrm{P}(3 \mathrm{HP})$ polymers as well as their binary blends measured by BOD method.

superimposition of those of the individual components $\mathrm{P}(3 \mathrm{HB})$ and $\mathrm{P}(3 \mathrm{HP})$, this may be the reason that the domain size of each constituent in the blend is extremely larger than the cross-area of an absorbed enzyme molecule $\left(17 \pm 8 \mathrm{~nm}^{2}\right),{ }^{22}$ leading to similar biodegradation as in the pure state.

Environmental biodegradation of the binary blends in the natural water was also done via BOD. BOD biodegradability was evaluated as

$$
\begin{aligned}
& \text { Biodegradability }(\%)= \\
& \frac{B O D(\text { exp. })-B O D(\text { blank })}{T h O D} \times 100 \%
\end{aligned}
$$

in which $T h O D$ is the theoretical biochemical oxygen demand calculated on the assumption that the reactions proceeded as follows

$$
\begin{array}{ll}
\left(\mathrm{C}_{4} \mathrm{H}_{6} \mathrm{O}_{2}\right)_{n}+\frac{9}{2} n \mathrm{O}_{2} \rightarrow 4 n \mathrm{CO}_{2}+3 n \mathrm{H}_{2} \mathrm{O} & \mathrm{P}(3 \mathrm{HB}) \text { (7) } \\
\left(\mathrm{C}_{3} \mathrm{H}_{4} \mathrm{O}_{2}\right)_{n}+3 n \mathrm{O}_{2} \rightarrow 3 n \mathrm{CO}_{2}+2 n \mathrm{H}_{2} \mathrm{O} & \mathrm{P}(3 \mathrm{HP}) \text { (8) }
\end{array}
$$

$B O D$ (exp.) and $B O D$ (blank) express BOD of an experimental sample and controlled-blank, respectively. In Figure 15, BOD biodegradability of the pure polymers and blends is depicted. Pure $\mathrm{P}(3 \mathrm{HB})$ or blend was environmentally degraded after an induction period of about 4 days, and finally approached equilibrium with biodegradability of about $70 \mathrm{~mol} \%$. This is consistent with Abe et al. ${ }^{27}$ that almost $20-30 \mathrm{~mol} \%$ organic compounds are utilized to generate biomass during BOD. The higher degradation of blends can be reasonably accounted for the immiscible phase structures as revealed in the former section. $\mathrm{P}(3 \mathrm{HP})$ in the pure state thus shows no biodegradability, whereas it was degraded in the blend regardless of component composition. Hence, the inducing effect from $\mathrm{P}(3 \mathrm{HB})$ on the biodegradation of $\mathrm{P}(3 \mathrm{HP})$ can, therefore, be demonstrated. In the case of environmental biodegradation, polymer chains are degraded into the water-soluble oligomers by extracellular depolymerase from environmental micro-organisms. The oligomers are digested by the degraders. Nishida et al. ${ }^{21}$ reported the $\mathrm{P}(3 \mathrm{HP})$ as the analogue of the substrate by $\mathrm{P}(3 \mathrm{HB})$ or $\mathrm{PCL}$ degrader. This unambiguously indicates that the biodegradation of $\mathrm{P}(3 \mathrm{HP})$ is induced by $\mathrm{P}(3 \mathrm{HB})$, and $\mathrm{P}(3 \mathrm{HP})$ is degraded as an analogue of the $\mathrm{P}(3 \mathrm{HB})$ type of substrate. The least amount of $\mathrm{P}(3 \mathrm{HB})$ for efficiently inducing biodegradation of chemosynthetic $\mathrm{P}(3 \mathrm{HP})$ at lower production cost is now under investigation.

\section{CONCLUSIONS}

Bacterial $\mathrm{P}(3 \mathrm{HB})$ and chemosynthetic $\mathrm{P}(3 \mathrm{HP})$, were blended via solvent casting. By DSC, polarized optical microscopy and X-ray diffraction diffractometer, thermal and crystallization of the binary blend were characterized. Two constituents in the blending state formed respective $\mathrm{P}(3 \mathrm{HB})$ and $\mathrm{P}(3 \mathrm{HP})$ types of crystalline structures over the whole range of blend composition. Judging from $T_{\mathrm{g}}$ by DSC, immiscibility between $\mathrm{P}(3 \mathrm{HB})$ and $\mathrm{P}(3 \mathrm{HP})$ in the melting state can be concluded. Although $\mathrm{P}(3 \mathrm{HB})$ and $\mathrm{P}(3 \mathrm{HP})$ share similar chain structures, significant differences in the morphologies of the individual spherulites were indicated not only in dimensions but also texture, and the micro-crystals of $\mathrm{P}(3 \mathrm{HP})$ were occluded in the intra- and/or inter-spherulitic region of $\mathrm{P}(3 \mathrm{HB})$ spherulites in the blend. Dynamic mechanical thermal analysis of the $50 / 50$ blend showed the blend to exhibit mechanical behavior similar to pure polymer $\mathrm{P}(3 \mathrm{HB})$, and the broad features of glass transition indicated the same immiscibility on a DMTA observation scale. $T_{1}^{\mathrm{H}}$ and $T_{1 \rho}^{\mathrm{H}}$ by the solid state ${ }^{13} \mathrm{C}$ NMR measurements confirmed that even on a scale of $T_{1}^{\mathrm{H}}$, the binary blends were immiscible. Enzymatic biodegradation of the pure polymers as well as blends by the A. faecalis $T 1$ depolymerase indicated biodegradation to increase in proportion to the composition of $\mathrm{P}(3 \mathrm{HP})$. However, in natural river water, pure $\mathrm{P}(3 \mathrm{HP})$ could not be degraded via BOD, its environmental biodegradability was confirmed when presents as one constituent of the binary blend.

Acknowledgments. The authors are grateful to Dr. H. Nishida of Tokuyama Co. (Tsukuba, Japan) for kindly supplying the chemosynthetic poly(3-hydroxypropionic acid) samples. The authors are also indebted to Prof. Y. Doi and Dr. K. Kasuya of the Institute of Chemistry and Physics Research (RIKEN) for preparation of depolymerase. This work was partially supported by a Grant-in-Aid for the International Joint Research in the Area of Global Environment from NEDO/RITE (1997).

\section{REFERENCES}

1. A. J. Anderson and E. A. Dawes, Microbiol. Rev., 54, 450 (1990).

2. Y. Doi, "Microbial Polyester," VCH Publisher, New York, N.Y., 1990.

3. P. J. Hocking and R. H. Marchessault, "Biodegradable Polymer," G. J. L. Griffin, Ed., Blakie Academic \& Professional, London, New York, 1994

4. Y. Inoue and N. Yoshie, Prog. Polym. Sci., 17, 571 (1992).

5. A. Steinbüchel and H. E. Valentin, FEMS Microbiol. Lett., 128, 219 (1995).

6. M. Hiramitsu and Y. Doi, Polymer, 34, 4782 (1993).

7. E. Shimamura, M. Scandola, and Y. Doi, Macromolecules, 27, 4429 (1994).

8. A. Cao, K. Kasuya, H. Abe, Y. Doi, and Y. Inoue, Polymer, 39, 
4801 (1998).

9. P. A. Holmes, Phys. Technol., 16, 32 (1985).

10. K. Nakamura, N. Yoshie, M. Sakurai, and Y. Inoue, Polymer, 35, 193 (1994)

11. A. Spyros and R. H. Marchessault, Macromolecules, 28, 6108 (1995)

12. F. Shi, R. D. Ashby, and R. A. Gross, Macromolecules, 30, 2521 (1997)

13. H. Verhoogt, B. A. Ramsay, and B. D. Favis, Polymer, 35, 5155 (1994).

14. R. Pearce, J. Jesudason, W. Orts, R. H. Marchessault, and S. Bloembergens, Polymer, 33, 4647 (1992).

15. R. Pearce, G. R. Brown, and R. H. Marchessault, Polymer, 35, 3984 (1994).

16. H. Abe, Y. Doi, M. M. Satkowski, and I. Noda, Macromolecules, 27, 50 (1994).

17. M. Avella and E. Martsucelli, Polymer, 29, 1731 (1988).

18. M. Avella, E. Martsucelli, and P. Greco, Polymer, 32, 1647 (1991).

19. M. Avella, E. Martsucelli, and M. Raimo, Polymer, 34, 3234 (1993).

20. Y. Azuma, N. Yoshie, M. Sakurai Y. Inoue, and R. Chûjô, Polymer, 33, 4763 (1992).

21. H. Nishida, S. Suzuki, and Y. Tokiwa, J. Environ. Polym. Degrad., 6, in press (1998).

22. K. Kasuya, Y. Inoue, and Y. Doi, Int. J. Biol. Marcomol., 19, 35 (1996).

23. Y. Kumagai and Y. Doi, Polym. Deg. Stab., 37, 253 (1992).
24. M. Yamashita, N. Hattori, and H. Nishida, Polym. Prepr., Jpn., 43, 3980 (1994)

25. S. Kwak, J. Kim , and U. Kim, Macromolecules, 29, 3560 (1996).

26. Y. Shirakura, T. Fukui, T. Saito, Y. Okamoto, T. Narikawa, K. Koide, K. Tomita, T. Takemasa, and S. Masamune, Biochim. Biophys. Acta, 880, 46 (1986).

27. H. Abe and Y. Doi, Macromolecules, 29, 8683 (1996).

28. R. Pearce and R. H. Marchessault, Polymer, 35, 3990 (1994).

29. D. Li and J. Brisson, Macromolecules, 29, 868(1996).

30. H. Abe, Y. Doi, H. Aoki, and T. Akehata, Macromolecules, 31, 1791 (1998)

31. K. Okamura and R. H. Marchessault, "Conformation of Biopolymers," G. N. Ramachandran, Ed., Academic Press, London, 1967.

32. T. Wasai, T. Saegusa, and J. Fukukawa, Kougyou Kagaku Zasshi, 67, 601 (1964).

33. J. Yoon, M. Chang, M. Kim, E. Kang, C. Kim, and I. Chin, J. Polym. Sci., Part B: Polym. Phys., 34, 2543 (1996).

34. N. J. Zumbulyadis, J. Magn. Reson., 53, 486 (1983).

35. X.-Q. Zhang and Y.-S. Wang, Polymer, 60, 1867 (2989).

36. J. Straka, P. Schmidt, J. Dybal, B. Schneider, and J. Spêvácek, Polymer, 36, 1147 (1996).

37. N. Parizel, F. Laupretre, and L. Monnerie, Polymer, 38, 3719 (1997).

38. K. Kasuya, Y. Inoue, K. Yamada, and Y. Doi, Polym. Deg. Stab., 48, 167 (1995).

39. K. Mukai, K. Yamada, and Y. Doi, Int. J. Biol. Macromol., 15, 361 (1993). 